\title{
Isolated right ventricular infarction following aortic valve replacement
}

\author{
Gloria Abreu, Catarina Vieira, Isabel Durães Campos, Jorge Marques
}

Cardiology Department, Hospital de Braga, Braga, Portugal

\section{Correspondence to} Dr Gloria Abreu, gloriappabreu@gmail.com

Accepted 19 February 2017

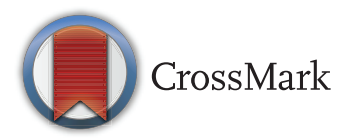

To cite: Abreu G, Vieira $C$ Campos ID, et al. BMJ Case Rep Published online: [please include Day Month Year] doi:10.1136/bcr-2016218811

\section{DESCRIPTION}

A woman aged 64 years, with a history of hypertension, symptomatic severe aortic stenosis and normal coronary arteries (figure 1), was submitted to aortic valve replacement with bioprosthesis Perimount Magna $21 \mathrm{~mm}$ and enlargement of the aortic root. Apart from atrial fibrillation, no electrocardiographic changes occurred in the postoperative period. She was discharged 7 days after surgery taking warfarin. Fifteen days later, she was readmitted in emergency department with oppressive chest pain radiating to back, hypotension, sweating and cold limbs. The 12-lead ECG showed junctional rhythm and mild ST segment elevation in V1-V3 leads, ST segment depression in inferolateral leads and an unequivocal ST segment elevation in right leads (figure 2A, B). Transthoracic echocardiogram disclosed dilation of right chambers, severe right ventricular dysfunction with akinesia of free wall and preserved left systolic function. On the blood sample, mild anaemia, hyperlactacidemia, INR 2.1 and normal values of troponin were noticed. Chest CT angiogram excluded aortic dissection and pulmonary artery embolism, evidence of right ventricle dilation (figure 2C). During the evaluation, she suffered two episodes of cardiac arrest, both reversed. She was intubated and supported with transvenous cardiac pacemaker, due to refractory bradycardia. Coronary angiogram revealed total occlusion of the right coronary artery at the ostium level, being impossible to advance the guide wire into this vessel (figure 2D, E). She was immediately transferred to cardiac surgery operating theatre with an intra-aortic balloon pump, high dose of aminergic and volume support. An emergent coronary bypass graft surgery with a saphenous vein was performed. Unfortunately, the patient died 1 day later due to cerebral hypoxia. No autopsy was conducted.

\section{Learning points}

- Isolated right ventricular infarction is a challenging diagnosis. It should be considered and promptly treated, when dealing with a patient presenting with cardiogenic shock. This case represents an example of acute myocardial infarction secondary to coronary ostial occlusion after aortic valve replacement (AVR), which is an unusual but potentially life-threatening complication. ${ }^{1}$

- Coronary ostial stenosis after AVR is estimated to occur in about $0.3-5 \%$ of all AVR procedures, and usually in the first 6 months postoperatively. Generally, it presents as acute coronary syndrome, left ventricular heart failure, ventricular arrhythmias or sudden death. ${ }^{2}$

- The exact mechanism underlying coronary ostial stenosis following AVR is unclear, but several hypotheses have been proposed. Selective anterograde ostial cannulation for administration of cardioplegic solution during surgery may cause initial mechanical vessel trauma producing immediate microinjuries or vessel wall hypoxia due to compression of vasa vasorum, with a delayed narrowing of the coronary ostia, by hyperplastic reaction. Embolism from debris, more often calcium related to aortic valve decalcification, ostial thrombosis from aortic retractor trauma and coronary artery spasm have also been described. Other possible causes of ostium compromise are fibrotic reaction at the level of valve sutures, valve sewing ring or aortotomy suture line. In addition, proximal aortic root thickening can occur as a reaction to turbulent flow around the prosthetic valve. An immunological reaction to the heterograft after AVR has also been reported. ${ }^{3} 4$
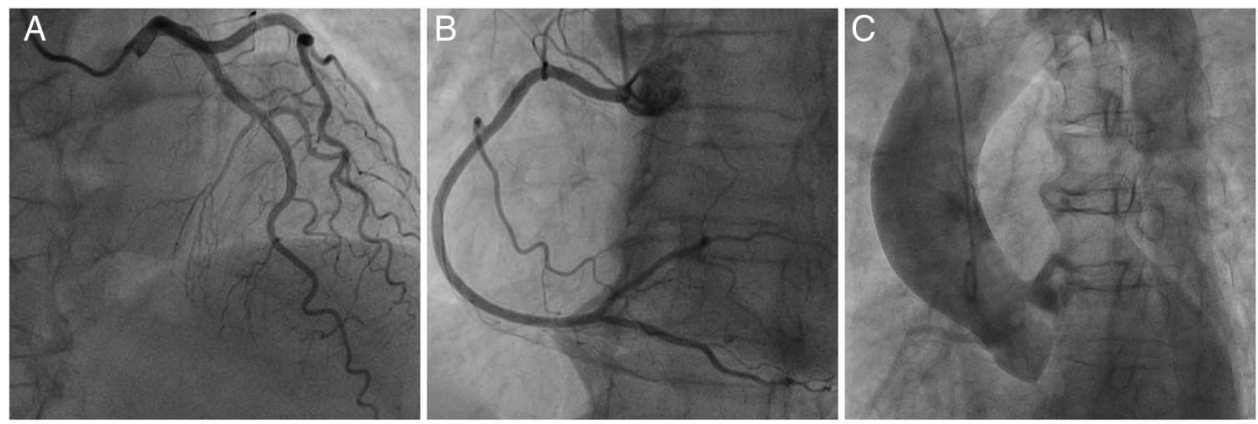

Figure 1 Coronary angiograms showing normal coronary arteries before aortic valve replacement (A: right anterior oblique projection with $20^{\circ}$ of cranial angulation showing the left anterior descendent artery, diagonal, septal branches and circumflex; B: $60^{\circ}$ left anterior oblique projection showing the right coronary artery; C: aortography showing a small aortic root and patency of the coronary ostia. 

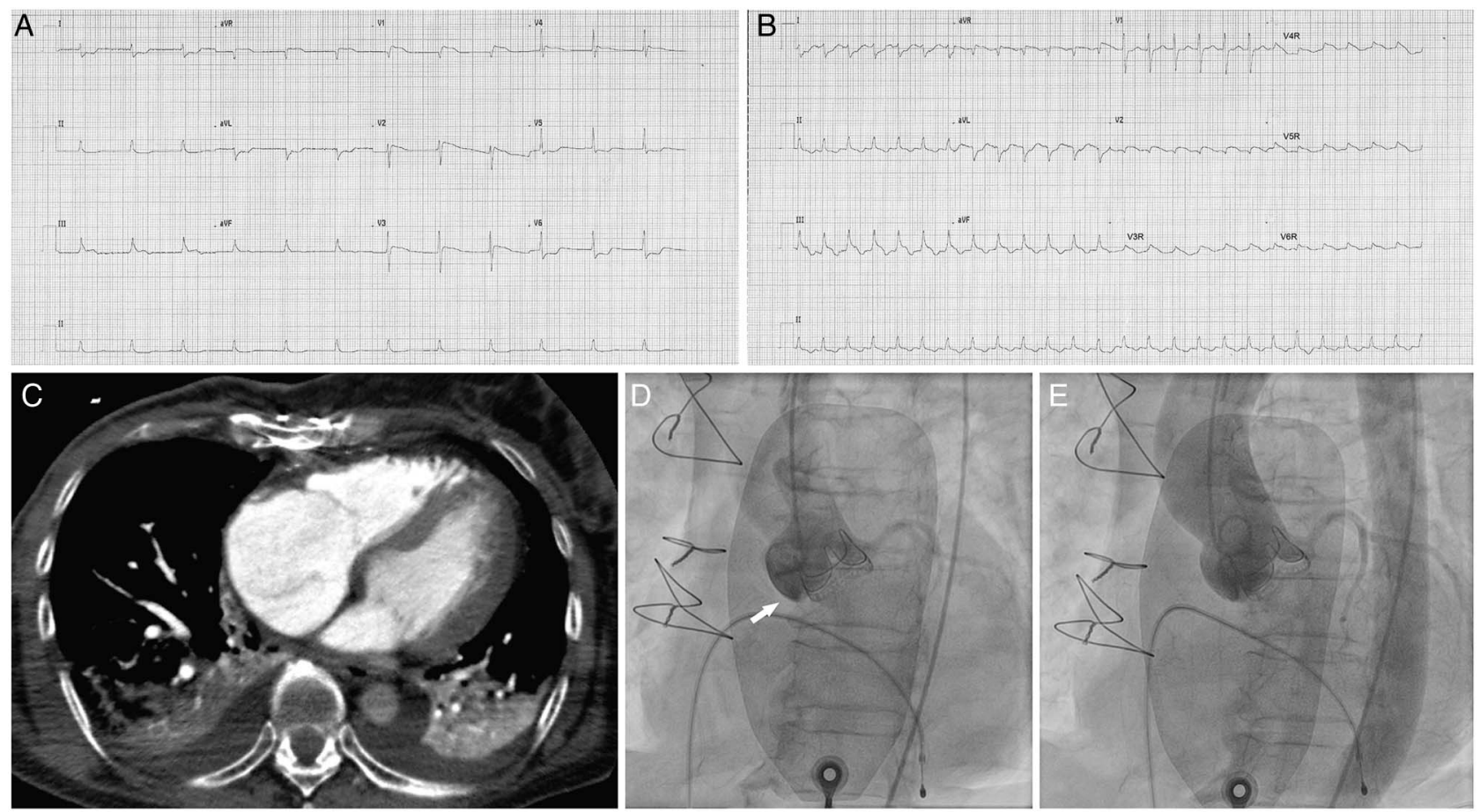

Figure 2 (A) Twelve-lead ECG showing mild ST segment elevation in V1-V3 leads and ST depression in the inferolateral leads. (B) Twelve-lead ECG showing unequivocal ST segment elevation in the right leads. (C) Chest CT angiogram disclosing dilation of the right chambers. (D) Unsuccessful attempt to perform right coronary angiogram (arrow); (E) aortography excluding aortic dissection.

Contributors GA and IDC collected the data. GA wrote the manuscript. CV was the doctor responsible for the case orientation. JM performed cardiac catheterisation and review the images. All the authors were involved in this clinical case and contributed to the conception of the work, reviewed the manuscript for important intellectual content and gave final approval of this article.

Competing interests None declared.

Provenance and peer review Not commissioned; externally peer reviewed.

\section{REFERENCES}

1 Yates JD, Kirsh MM, Sodeman TM, et al. Coronary ostial stenosis, a complication of aortic valve replacement. Circulation 1974;49:530-4.

2 Funada A, Mizuno S, Ohsato K, et al. Three cases of iatrogenic coronary ostial stenosis after aortic valve replacement. Circ J 2006;70:1312-17.

3 Todaro MC, Lelasi A, Silvestro A, et al. An unusual case of cardiogenic shock late following surgical aortic valve replacement. J Cardiol Cases 2016:13:162-4.

4 Pillai JB, Pillay TM, Ahmad J. Coronary ostial stenosis after aortic valve replacement, revisited. Ann Thorac Surg 2004:78:2169-71.

Copyright 2017 BMJ Publishing Group. All rights reserved. For permission to reuse any of this content visit http://group.bmj.com/group/rights-licensing/permissions.

BMJ Case Report Fellows may re-use this article for personal use and teaching without any further permission.

Become a Fellow of BMJ Case Reports today and you can:

- Submit as many cases as you like

- Enjoy fast sympathetic peer review and rapid publication of accepted articles

- Access all the published articles

- Re-use any of the published material for personal use and teaching without further permission

For information on Institutional Fellowships contact consortiasales@bmjgroup.com

Visit casereports.bmj.com for more articles like this and to become a Fellow 